Review Article

\title{
Risk of Tuberculosis Reactivation in Patients with Rheumatoid Arthritis, Ankylosing Spondylitis, and Psoriatic Arthritis Receiving Non-Anti-TNF-Targeted Biologics
}

\author{
Fabrizio Cantini, ${ }^{1}$ Carlotta Nannini, ${ }^{1}$ Laura Niccoli, ${ }^{1}$ Linda Petrone, ${ }^{2}$ \\ Giuseppe Ippolito, ${ }^{3}$ and Delia Goletti ${ }^{2}$ \\ ${ }^{1}$ Department of Rheumatology, Hospital of Prato, Prato, Italy \\ ${ }^{2}$ Translational Research Unit, Department of Epidemiology and Preclinical Research, National Institute for Infectious Diseases \\ "L. Spallanzani", Rome, Italy \\ ${ }^{3}$ Scientific Direction, National Institute for Infectious Diseases "L. Spallanzani”, Rome, Italy
}

Correspondence should be addressed to Fabrizio Cantini; fbrzcantini@gmail.com

Received 24 January 2017; Accepted 28 March 2017; Published 1 June 2017

Academic Editor: Anshu Agrawal

Copyright (c) 2017 Fabrizio Cantini et al. This is an open access article distributed under the Creative Commons Attribution License, which permits unrestricted use, distribution, and reproduction in any medium, provided the original work is properly cited.

\begin{abstract}
Tuberculosis (TB) still represents an important issue for public health in underdeveloped countries, but the use of antitumor necrosis factor agents (anti-TNF) for the treatment of inflammatory rheumatic disorders has reopened the problem also in countries with low TB incidence, due to the increased risk of TB reactivation in subjects with latent tuberculosis infection (LTBI). Over the last 5 years, several non-anti-TNF-targeted biologics have been licensed for the treatment of rheumatoid arthritis, ankylosing spondylitis, and psoriatic arthritis. We reviewed the epidemiology of TB, the role of different cytokines and of the immune system cells involved in the immune response against TB infection, the methods to detect LTBI, and the risk of TB reactivation in patients exposed to non-anti-TNF-targeted biologics. Given the limited role exerted by the cytokines different from TNF, as expected, data from controlled trials, national registries of biologics, and postmarketing surveillance show that the risk of TB reactivation in patients receiving non-anti-TNF-targeted biologics is negligible, hence raising the question whether the screening procedures for LTBI would be necessary.
\end{abstract}

\section{Introduction}

Antitumor necrosis factor-targeted agents (anti-TNFs) infliximab and etanercept were licensed around 20 years ago, and over the following years, other anti-TNFs such as adalimumab, golimumab, and certolizumab pegol were approved. These drugs have changed the natural history of inflammatory rheumatic disorders including rheumatoid arthritis (RA), ankylosing spondylitis (AS), and psoriatic arthritis (PsA), with good control of symptoms and arrest or lowering of the disease progression. Nevertheless, it has long been recognized that the anti-TNFs are associated with increased risk of reactivation of latent tuberculosis infection (LTBI) [1-4].
In recent years, non-anti-TNF-targeted biologics, including anti-interleukin- (IL-) 1 anakinra (ANK), IL-6 inhibitor tocilizumab (TCZ), anti-CD20 rituximab (RTX), anti-CD28 abatacept (ABA), anti-IL-12 and IL-23 (UTK), and anti IL17 secukinumab (SCK), were licensed for the treatment of RA (ANK, TCZ, RTX, and ABA), AS (UTK), and PsA (UTK and SCK). Since the use of ANK in RA is actually very limited due to its lower efficacy as compared with that of other biologics, data on TB risk associated with this biologic, previously discussed elsewhere [5], were not included in this manuscript.

The aim of this paper was to assess the tuberculosis (TB) risk in patients with rheumatic diseases receiving non-antiTNF-targeted biologics. Moreover, the epidemiology of TB 
and the role of different cytokines (TNF- $\alpha$, IL-6, IL-17, IL-12, and IL-23) in immune response against Mycobacterium tuberculosis (MTb) were reviewed.

\section{Methods}

A systematic review of the literature using PubMed database was performed to identify English-language articles related to all clinical trials and data from postmarketing surveillance and from national registries of currently employed nonanti-TNF-targeted biologics for rheumatic diseases to identify all cases of TB complicating the underlying rheumatic disease course. Data were extracted from phase II- and IIIrandomized controlled trials of at least a 12-week duration, their extension phase studies, and from prospective, openlabel studies focused on the efficacy and safety of each drug. In addition, available data from biologic national registries, national healthcare databases, and postmarketing surveillance surveys were included. Reviews and meta-analyses were excluded. In the absence of data from registries and postmarketing surveillance, single-case reports of TB occurrence during the treatment with the most recent biologics were included. The following drugs were investigated: TCZ, RTX, ABA, UTK, and SCK. The research was performed by crossing the single drug with the following key terms: epidemiology, TNF- $\alpha$, IL-6, IL-17, IL-12, IL-23, latent tuberculosis infection, tuberculosis, infections, comorbidities, and safety. The number of publications, the type of trial, the number of enrolled patients, the number of TB cases, and, when possible, the setting where TB cases occurred were recorded for each biologic. Moreover, the most relevant literature on TB epidemiology, immune mechanisms against TB infection, and methods to detect LTBI was reviewed. The literature review was extended to December 31, 2016.

\section{Results}

3.1. Epidemiology of $T B$ in Different Countries. $\mathrm{TB}$ is still a leading cause of morbidity and mortality in the world [6], accounting for about 10.4 million new cases and 1.4 million deaths annually. Of note, more than two thirds of the global TB burden is reported in Africa and Asia, and in absolute terms, six countries accounted for $60 \%$ of the new cases: India, Indonesia, China, Nigeria, Pakistan, and South Africa. The poorest and socially excluded groups own the largest burden of disease emphasizing the need to invest on the management of the social determinants of health through poverty reduction measures and targeted interventions on high-risk populations.

The spread of multidrug-resistance TB requires special attention [7] and highlights the need to foster research on TB diagnostics, new drugs, and vaccines [8]. Although many advances have been made in the fight against TB over the last twenty years, a lot is still needed to achieve global elimination [8-11].

3.2. Role of Different Cytokines (TNF- $\alpha, I L-1, I L-6, I L-17, I L-$ 12, and IL-23) in Immune Response against MTb. Although many components of the host immune response against
MTb are known, the specific biomarkers and mechanisms underlying protective immunity remain obscure $[8,12,13]$. In addition to host and environmental factors, the genetic variation in $\mathrm{MTb}$ also plays a role in the clinical phenotypes of TB [14]. However, little is known about the interaction between human and MTb genetic diversity, and it has been argued that new paradigms and new conceptual frameworks are required to better understand and ultimately better control TB globally [15].

Upon MTb infection, active TB develops in some patients, whereas others contain the initial infection, and the disease is considered latent (asymptomatic). Among those latently infected, 5 to $10 \%$ will progress to active TB. Current understanding suggests that in subject with LTBI, which are estimated to be one fourth of the world's population [16], the infection is controlled by an active host immune system, whereas in patients with active TB, there is an uncontrolled bacterial growth due to an ineffective immune response which relies on the cooperation between innate and adaptive immunity. Until recently, LTBI was thought to represent a uniform state. However, it has become clear that LTBI has to be considered as a broad spectrum of infection states that differ by the degree of the pathogen replication, host resistance, and inflammation [17-19]. Although the immune system controls the infection, this control does not necessarily lead to sterilization. Once MTb is in the macrophages, the protective immune response against mycobacteria is dependent on the interaction between these host cells and CD $4^{+} \mathrm{T}$ cells. T cell-mediated immune response begins after the dissemination of MTb to the lymph nodes [20, 21]. Here, the antigen-specific $\mathrm{T}$ cells proliferate and then migrate to the infected lungs where they are found, together with other leukocytes, as part of the granulomas. Several distinct types of T helper (Th) cells (Th1, Th2, Th17, and regulatory T cells) are present at the site of infection.

The main Th1 cytokines are interferon- $\gamma($ IFN- $\gamma)$, IL-12, and TNF- $\alpha$. IFN- $\gamma$ is mainly produced by the CD 4 T cells whereas IL-12 and TNF- $\alpha$ by the antigen presenting cells (APCs). Th1 cells play an essential role in MTb control through the IFN- $\gamma$ secretion enhancing the macrophage microbicidal mechanisms because they activate signaling pathways that include the inducible nitric oxide synthase (iNOS) pathway [22] and induce the process of acidification and maturation of phagosomes and autophagy [23-26]. IFN- $\gamma$ is crucial for the defense against MTb. Individuals with mutations in the IL-12/IFN- $\gamma$ axis develop disseminated infection caused by BCG or nontuberculous species of mycobacteria [27].

Th17 cells are characterized by production of IL-17A/F and IL-22, have strong proinflammatory capacities, and play a significant role in mucosal immunity. In animal models of $\mathrm{TB}$, the presence of Th17 cells was associated with protection, and removal of IL-17-producing cells enhanced recruitment of Th1 cells to the lung [28]. IL-17 has been shown to have a protective immunity against hypervirulent MTb strains [29]. In addition, the magnitude of the Th17 response was found to be important, since mice repeatedly exposed to MTb and BCG developed strong IL-23-induced Th17 cell responses that became pathogenic rather than protective, with an IL-17/macrophage inflammatory protein-2-(MIP-2-) 
dependent influx of neutrophils and induction of lung pathology rather than containment of infection [30].

The crossregulation of Th1 and Th17 populations seems to be crucial for protection against MTb to reduce the inflammation-induced damage [31]. It has been shown that IFN- $\gamma$ inhibits the production of IL- 17 by $\mathrm{CD}^{+}{ }^{+} \mathrm{T}$ cells, reducing the survival of neutrophils and the accumulation of these cells in infected lungs contributing to a diminution of the inflammation [32]. These data suggest that IFN- $\gamma$ appears to limit the population IL-17-producing cells.

Despite the important role of IFN- $\gamma$, IL-12, and IL-17 in the fight against MTb, several studies based on the knockout mice model have shown that also TNF- $\alpha$, granulocyte-macrophage colony-stimulating factor (GM-CSF), IL-1, and IL-6 are crucial components of MTb control growth [33].

In particular, TNF- $\alpha$ has been associated with the maintenance of granuloma integrity, and changes in its levels have been correlated with disease susceptibility both in experimental models and in human patients [34-37]. In fact, TNF- $\alpha$ acts synergistically with IFN- $\gamma$ to stimulate the production of nitric oxide (NO) by macrophages and influences the expression of chemokines, such as CCL5, CCL9, CXCL10, and CCL2, which induce migration to and maintenance of immune cells in the infection site [38].

IL- $1 \beta$ is essential for host resistance to MTb, as shown in the murine model in which IL- $1 \beta$ decreases MTb replication activating the innate antimicrobial activity through the recruitment of TNF, upregulation of cell surface TNFR expression, and caspase-3 activation [39]. Moreover, IL-1 $\beta$ contributes to the host protection against MTb through the induction of PGE2 synthesis regulating in this way also its own production. In particular, PGE2 decreases type I IFN response [40] which is increased in active TB [41] and it is a down modulator of IL-1 secretion in addition to other cytokines required for effective MTb clearance (i.e., IL-12 and TNF- $\alpha[42,43])$.

IL-6 has both pro- and anti-inflammatory properties and it is involved in the Th17 and Th22 cell differentiation both important for antimycobacterial activity [44, 31]. It is produced early during mycobacterial infection and is involved in macrophage and cytotoxic T-cell differentiation [45]. Lethal TB has been described in IL-6-deficient mutant mice [46].

As summarized in Figure 1, immune protection against TB depends on several immune components. Here, we analyzed mainly the crossregulation of Th1 and Th17 populations and the production of TNF- $\alpha$, IL-12, IL-1, and IL- 6 as important players in TB control.

3.3. Review of Methods to Detect LTBI: Sensitivity, Specificity, Confounding Factors, and Limits. From an operational point of view, LTBI is defined as a state of persistent immune response to MTb antigens detected either by the tuberculin skin test (TST) or by IGRA without evidence of clinically manifested tuberculosis. Therefore, LTBI subjects carry an increased risk of progression to TB which is augmented in LTBI individuals with immune impairment as HIV coinfection [47] or therapies with TNF- $\alpha$ inhibitors [1, 3, 48, 49] or other immune regulators used for inflammatory diseases and transplantation [50] or compromised immunity due to noncommunicable diseases, such as type 2 diabetes $[51,52]$.

The TST and IGRA tests are based on immunological sensitization to mycobacterial antigens. TST response is quantified by the skin induration resulting from intradermal injection of purified protein derivative (PPD), a crude mixture of antigens, many of which are shared by MTb, M. bovis, Bacillus Calmette et Guérin (BCG) and several species of environmental mycobacteria. Blood-based IGRA, including QuantiFERON TB Gold In-Tube (Qiagen; QFT-GIT) and T-SPOT.TB (Oxford Immunotec), measures in vitro IFN- $\gamma$ production upon antigen stimulation of the whole blood by enzyme-linked immunosorbent assay (ELISA) or peripheral blood mononuclear cells (PBMC) by enzyme-linked immunospot (ELISPOT) assay, respectively [53]. The specificity of these assays is due to the stimulation with peptides spanning MTb antigens ESAT-6, CFP-10, and TB7.7 for QFT-GIT that are restricted to a region of the MTb genome deleted from M. bovis Bacillus Calmette et Guerin and which is not present in most environmental mycobacteria [54-57].

Advantages of IGRA are due to the fact that they require only a single laboratory test with negative and positive controls and only one visit. Moreover, the in vitro tests may distinguish true negative responses from anergy [53]. Recently, an updated version of the QFT-GIT has been launched [58]. The QuantiFERON TB Plus includes an additional antigen tube to QFT-GIT, which contains peptides that are intended to specifically induce a CD8 T-cell response in addition to the $\mathrm{CD} 4 \mathrm{~T}$-cell response [59] detected with the original QFT-GIT assay $[59,60]$. The new CD8-specific peptides have been added to increase the sensitivity of the test because it has been shown that MTb-specific $\mathrm{CD}^{+} \mathrm{T}$ cells are mainly associated to active TB [61-66]; that, if detected in LTBI, they are associated with a recent exposure to $\mathrm{MTb}$ [67]; and that they decline after anti-TB treatment $[64,68]$. The first data on performance of QuantiFERON TB Plus were reported recently [69-72].

A new promising test for LTBI detection is the C-Tb [73] which is a skin test measuring the hypersensitivity to recombinant ESAT-6 and CFP-10 proteins following intradermal administration. The authors claim that it combines the strengths and advantages of TST and IGRA technologies, the ease of use and low cost of TST, and a high-specificity analogous to IGRAs. Another test, based on Rv3615c encoded outside the RD1 region, has been shown to have potential as a new T-cell-based immunodiagnostic [74, 75].

Beside the advantages, TST and IGRAs present limitations. They are characterized by low accuracy in immunecompromised patients and cannot distinguish between LTBI and active TB disease [53]. The latter is a major issue in TBendemic areas and leads to poor predictive value for development of TB in persons with LTBI $[53,75,76]$. Therefore, it is crucial to find biomarkers that can differentiate between active and quiescent bacterial replication in persons with LTBI or host markers that identify those with LTBI who are at risk of developing active disease [62, 77-84].

3.4. Non-Anti-TNF-Targeted Biologics for RA. Table 1 summarized the current licensed biologics for the treatment of 


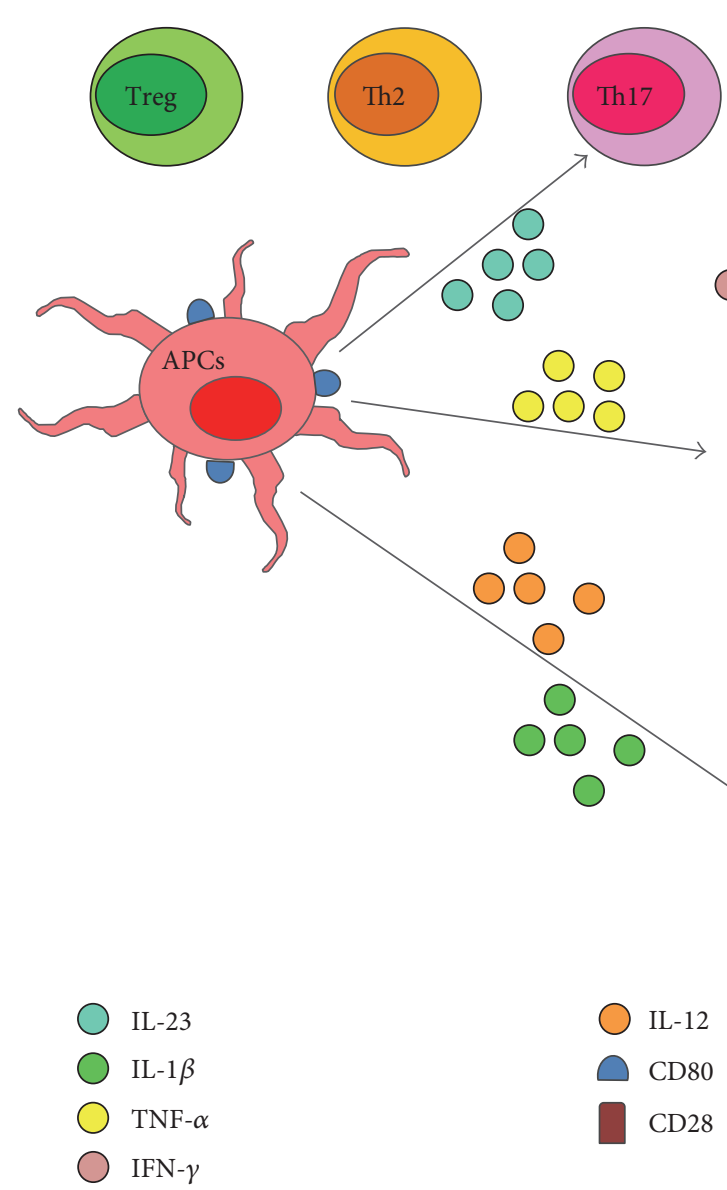

FIGURE 1: Schematic representation of the immune cells involved in Mycobacterium tuberculosis infection. Distinct types of T helper (Th) cells as Th1, Th2, Th17, and regulatory T cells (Treg) are present at the site of Mycobacterium tuberculosis (MTb) infection. These cells exert their functions mainly through soluble factors. In particular, Th1 cells producing IFN- $\gamma$ play an essential role in MTb clearance enhancing the macrophage microbicidal mechanisms through the activation of the iNOS pathway and the induction of phagosomes acidification, maturation, and autophagy. Moreover, tumor necrosis factor- (TNF-) $\alpha$, produced by antigen presenting cells (APCs) after MTb stimulation, acts synergically with IFN- $\gamma$ thus contributing to MTb control. APCs produce also interleukin- (IL-) 12 and IL- $1 \beta$ that are essential for resistance to MTb. Moreover, IL-23 produced by APC induces the differentiation of Th17 cells producing IL-17, IL-17F, IL-6, and TNF- $\alpha$. Th17 cells are associated with MTb protection; however, when Th17 cell responses became pathogenic rather than protective, Th1 cells are induced to stop these dangerous effects. Finally, the role of Th2, Treg, and B-cell subsets in human disease still remains controversial and needs further elucidations.

inflammatory disorders and their action on cells and cytokines of immune response.

3.4.1. Tocilizumab. TCZ is a recombinant, humanised, monoclonal, anti-IL-6 receptor antibody competing for both the membrane-bound and soluble forms of human IL-6 receptor with inhibition of the binding of IL- 6 to its receptors and its proinflammatory activity. The drug, both for intravenous or subcutaneous administration, is currently approved combined or in monotherapy for the treatment of rheumatoid arthritis (RA). The literature search disclosed 30 clinical trials of 15,485 patients with RA with a clinical observation ranging from 14 weeks to 5 years [85-114]. Notably, in 19 studies, LTBI screening procedures and TB reactivation prophylaxis were not included in the protocol as an inclusion criteria [85-104]. Overall, no TB cases were observed, though the 24-week duration of most studies may have led to underestimate the occurrence of active TB. However, also in the long-term trial, active TB cases did not occur [102, 109-114]. Equally, no TB cases were recorded in the only one registry of 302 RA patients treated with TCZ [115].

In a postmarketing Japanese surveillance [116], 4 cases of active TB were observed in 3881 patients. TB occurred after with an interval ranging from 24 days to 4 months after the beginning of TCZ therapy, with an incidence of $0.22 / 100 /$ year, which is lower than the reported incidence of 15/100/year in Japan [117].

In the real life, 8 patients receiving TCZ and developing active TB were reported [118], but all cases were observed in countries at high TB risk, including Thailand, Spain, South Africa, Peru, Singapore, Brazil, and Mexico.

To summarize, data on a large number of TCZ exposed from clinical trials indicate a very low or absent risk of TB reactivation. Sporadic cases reported from the daily clinical practice occurred in high TB risk countries, 
TABLE 1: Immune cells and factors involved in the immunity against tuberculosis. List of some of the biological drugs used in the treatment of rheumatological disorders that inhibit immune paths.

\begin{tabular}{|c|c|c|c|c|}
\hline Cytokine & $\begin{array}{c}\text { Producing cell } \\
\text { type }\end{array}$ & Role in tuberculosis & $\begin{array}{l}\text { Biological drug inhibiting } \\
\text { this path }\end{array}$ & References \\
\hline IFN- $\gamma$ & T lymphocytes, NK & $\begin{array}{l}\text { (1) Activates iNOS pathway } \\
\text { (2) Induces the process of acidification and maturation } \\
\text { of phagosomes } \\
\text { (3) Induces autophagy } \\
\text { (4) Inhibits IL-17 production }\end{array}$ & & {$[22,23-26,32]$} \\
\hline TNF- $\alpha$ & $\begin{array}{l}\text { T lymphocytes, } \\
\text { macrophages }\end{array}$ & $\begin{array}{l}\text { (1) Maintain of granuloma integrity } \\
\text { (2) Changes in TNF- } \alpha \text { levels have been correlated with } \\
\text { disease susceptibility } \\
\text { (3) Acts synergistically with IFN- } \gamma \text { to stimulate the } \\
\text { production of NO by macrophages } \\
\text { (4) Influences the expression of chemokines }\end{array}$ & $\begin{array}{l}\text { Infliximab, etanercept, } \\
\text { adalimumab, abatacept }\end{array}$ & [34-38] \\
\hline IL-12 & $\begin{array}{l}\text { Macrophages, } \\
\text { dendritic cells }\end{array}$ & $\begin{array}{l}\text { (1) Individuals with mutations in the IL-12/IFN- } \gamma \text { axis } \\
\text { develop disseminated infection caused by BCG or } \\
\text { nontuberculous species of mycobacteria } \\
\text { (2) Important for MTb clearance }\end{array}$ & Ustekinumab & {$[27,42,43]$} \\
\hline IL-23 & $\begin{array}{l}\text { Macrophages, } \\
\text { dendritic cells }\end{array}$ & $\begin{array}{l}\text { (1) Mice repeatedly exposed to MTb and BCG } \\
\text { developed strong IL-23-induced Th17 cell pathogenic } \\
\text { responses }\end{array}$ & Ustekinumab & [30] \\
\hline IL-6 & $\begin{array}{l}\text { T lymphocytes, } \\
\text { macrophages }\end{array}$ & $\begin{array}{l}\text { (1) Pro- and anti-inflammatory properties } \\
\text { (2) Involved in the Th17 and Th22 cell differentiation } \\
\text { (3) Early produced during mycobacterial infection } \\
\text { (4) Involved in macrophage and cytotoxic T-cell } \\
\text { differentiation } \\
\text { (5) IL-6-deficient mice develops lethal TB }\end{array}$ & Tocilizumab & {$[31,44-46]$} \\
\hline IL-17 & CD4 T cells & $\begin{array}{l}\text { (1) Has protective immunity against hyper-virulent } \\
\text { MTb strains } \\
\text { (2) Removal of IL-17-producing cells enhanced } \\
\text { recruitment of Th1 cells to the lung } \\
\text { (3) Has pathogenic role of Th17 cells during chronic } \\
\text { infection with MTb or BCG in mice }\end{array}$ & Secukinumab & [28-30] \\
\hline IL- $1 \beta$ & Macrophages & $\begin{array}{l}\text { (1) Decreases MTb replication activating the innate } \\
\text { antimicrobial activity } \\
\text { (2) Induces PGE2 synthesis that leads to a decrease } \\
\text { of type I IFN response }\end{array}$ & Anakinra & \\
\hline
\end{tabular}

IFN: interferon; TNF: tumor necrosis factor; IL: interleukin; NK: natural killer; iNOS: inducible nitric oxide synthase; NO: nitric oxide; BCG: Bacillus Calmette-Guérin; MTb: Mycobacterium tuberculosis; Th: T helper; PGE2: Prostaglandin E2.

thus raising the concern of a primary $\mathrm{TB}$ infection rather than LTBI reactivation.

3.4.2. Rituximab. RTX is a chimeric mouse-human monoclonal antibody that selectively depletes the $\mathrm{CD}_{2} 0^{+}$peripheral B-cell subpopulation via multiple mechanisms, including antibody-dependent cellular toxicity, complement-mediated lysis, and induction of apoptosis [119]. RTX obtained the FDA approval for the treatment of RA in 2006 at the standardized dosage of 2 infusions of $1000 \mathrm{mg}$ each at a 2-week interval with retreatment after 6 months. As expected, due to its B-lymphocytes-targeted action, no cases of active TB were recorded in 9 RCTs of RTX in a total number of 3623 patients with RA [120-128] and in 9 open-label studies in 1191 patients with the same disease [129-137]. An analysis of 3194 RA patients recruited in 8 RCTs and 2 long-term open-label extension trials followed for 9.5 years and receiving up to 17 RTX courses disclosed 2 cases of active pulmonary TB [138]. Data on the demographic and clinical features of these 2 patients, concomitant therapies, additional risk factors for TB, and the country of origin are not available. Previously, in a survey from the Infectious Diseases Society of America, members of the Emerging Infections Network, 3 cases of active TB were reported in patients treated with RTX, but no further description of these patients is available [139]. Recently, a nationwide retrospective cohort study from Taiwan, a country at high TB risk, reported 2 cases of active TB in 763 patients with RA treated with RTX [140]. These 2 patients had a history of previous antiTNF treatment, and active TB occurred after 8 and 10 years of RTX therapy.

Another case of TB knee arthritis in a 42-year-old woman patient receiving RTX has been published [141]. This patient was not screened for LTBI and she was living in Cambodia, a country at high TB risk.

Confirming the low risk of $\mathrm{TB}$ reactivation, no cases of active TB were observed in 1303 RA patients included in the French AIR registry who had received at least 2 RTX 
courses [142], in 370 patients with different autoimmune diseases in the GRAID registry from Germany [143], in 234 in Greece [144], while 1 TB case was recorded in 2484 RTXexposed RA patients in the German GERINIS registry [145].

The low or absent risk of TB reactivation associated with RTX administration has been confirmed by two other studies on 56 RA patients at high TB risk [146] and on patients previously treated for active TB [142, 147, 148].

In conclusion, in patients with rheumatic diseases receiving $\mathrm{RTX}$, the TB risk is negligible, and according to the Rituximab Consensus Expert Committee [149], the screening procedures for LTBI before therapy starting seem unnecessary.

3.4.3. Abatacept. ABA is a soluble fully human fusion protein blocking the activation of $\mathrm{T}$ cells by binding with costimulatory proteins present on APCs (CD80/86 on APCs and CD28 on T cells) [150]. The drug has been approved for the treatment of RA and it is administered intravenously every 4 weeks at the dose of $10 \mathrm{mg} / \mathrm{Kg}$ or subcutaneously at a weekly dose of $125 \mathrm{mg}$.

Though the reduced expression of CD8/CD28 T cells exerted by ABA may reduce the immune response against TB infection [151], only 1 case of presumptive active TB was registered in 17 trials of $\mathrm{ABA}$ administered either intravenously or subcutaneously in 8539 patients with RA [150, 152-167]. The reported TB case was described in the 3-year-extension phase of the AIM study [168]. An ABAexposed 39-year-old woman was diagnosed as having TB because she was responsive to TB therapy, but bronchial lavage and biopsy were negative. Two more cases of active TB were observed in the 5- and 7-year long-term extension phases of the same trial $[169,170]$.

Data from real-life practice showed no TB cases in 682 patients included in the ORA French registry [171], and no single case description of $\mathrm{TB}$ in patients treated with ABA is reported.

More recently, no TB cases occurred in 231 ABAexposed patients who were enrolled in a Japanese multicentre registry [172].

To conclude, active TB in ABA-exposed patients is a rare event and, far apart, less frequent than that in the general population, thus suggesting the screening procedures for LTBI as unnecessary.

\subsection{Non-Anti-TNF-Targeted Biologics for PsA and AS}

3.5.1. Ustekinumab. UTK is a fully human monoclonal antibody directed against the p40 subunit common to IL-12 and IL-23, thereby blocking the interaction of IL-12 and IL-23 with their cell surface receptors [173]. Consequently, the inflammatory pathways Th1 IL-12 and Th17 IL-23 dependent, which are strongly implicated in the pathogenesis of psoriasis and PsA, are inhibited [174]. Based upon 1 phase II [175] and 2 large phase III trials $[176,177]$ enrolling a total of 1073 patients, UTK was approved for the treatment of PsA. Beyond its efficacy, UTK demonstrated an excellent safety profile with respect to overall infections. No cases of active TB were recorded in the 3 trials both in a short-term period and after 2 years of treatment [178]. Moreover, in a subanalysis of 5 trials of UTK in psoriasis and PsA, no cases of active TB developed in 167 patients positive for LTBI [179]. Confirming the absence of TB reactivation risk, data from the Psoriasis Longitudinal Assessment and Registry (PSOLAR), including 3474 patients with psoriasis and PsA receiving UTK, indicate the absence of TB cases over a median follow-up of 1.60 years [180]. Therefore, UTK may ensure an effective and safe treatment in LTBI-positive PsA patients.

3.5.2. Secukinumab. The results of efficacy and safety from 3 controlled trials of PsA [181-183] and 2 trials of AS $[184,185]$, respectively, enrolling a total number 1045 and 620 patients, led to the approval of SCK, a fully human monoclonal antibody targeting and neutralizing IL-17A, for the treatment of the two rheumatic disorders. No cases of TB reactivation were recorded, and the same resulted from a pooled safety analysis of 10 studies of SCK in psoriasis [186].

SCK has been recently marketed and data from real-life clinical practice are lacking. However, its mechanism of action and the safety results from clinical studies indicate that the drug is safe with respect to TB reactivation and may represent a good therapeutic option in patients with PsA and AS who are at increased risk of TB.

\section{Discussion}

Over time, in developed countries, TB has been characterized by a fluctuating epidemiology with a peak in the 18th and 19th centuries and a progressive reduction of incidence over the 20th century [187]. A resurgence of the disease was recorded after the introduction of anti-TNF- $\alpha$-targeted therapies for the treatment of RA, PsA, and AS. Indeed, TNF- $\alpha$ blocking negatively interferes with the TB granuloma formation and maintenance and the growth of $\mathrm{MTb}$, thus facilitating the reactivation of $\mathrm{TB}$ [4]. The problem was reduced after the adoption of screening procedures to detect LTBI; however, an increased risk of TB reactivation in antiTNF-exposed patients is still currently observed [4].

During the last 10 years, new inflammatory pathways sustained by CD20 and CD28 lymphocytes and cytokines other than TNF- $\alpha$, including IL-6, IL-12, IL-23, and IL-17, have been discovered with consequent development of biologics directed against these new targets.

Theoretically, these new targeted therapies, acting on cells of cytokines scarcely or not involved in the immune response against the $\mathrm{TB}$ infection, would be safer than anti-TNFs in LTBI-positive patients with RA, PsA, and AS. As expected, in our review, we found reassuring data concerning the risk of $\mathrm{TB}$ reactivation associated with TCZ, RTX, and ABA in patients with RA and with UTK and SCK in those with PsA and AS, respectively. Indeed, only sporadic cases of active TB, not exceeding the frequency of the disease in general population, were reported in TCZ-, RTX-, and ABA-exposed patients with RA, and no cases were associated with UTK and SCK in patients with PSA and AS (Table 2). In our opinion, these data greatly influence the management of patients with RA, PsA, and AS requiring biologic therapies. Indeed, LTBI positivity represents an 
TABLE 2: Non-anti-TNF-targeted biologics: reported TB cases from national registries and postmarketing surveillance.

\begin{tabular}{|c|c|c|c|c|c|}
\hline Biologic & Country; patient $\mathrm{N}^{\circ}$ & TB cases & IR & Expected IR/100/year (WHO) & Reference \\
\hline \multirow{2}{*}{ Tocilizumab } & Japan; 3881 & 4 & 0.22 & $15-100$ & [116] \\
\hline & Japan; 302 & 0 & 0 & $15-100$ & [115] \\
\hline \multirow{5}{*}{ Rituximab } & France; 1303 & 0 & 0 & $10-24$ & [142] \\
\hline & Germany; 370 & 0 & 0 & $10-24$ & [143] \\
\hline & Germany; 2484 & 1 & 0.12 & $10-24$ & [145] \\
\hline & Greece; 234 & 0 & 0 & $10-24$ & [144] \\
\hline & Taiwan; 763 & 2 & 0.38 & $15-100$ & {$[140]$} \\
\hline \multirow{2}{*}{ Abatacept } & France; 682 & 0 & 0 & $10-24$ & {$[171]$} \\
\hline & Japan; 231 & 0 & 0 & $15-100$ & {$[172]$} \\
\hline Ustekinumab & Worldwide; 3474 & 0 & 0 & NA & {$[180]$} \\
\hline Secukinumab & Unavailable data & NA & NA & NA & NA \\
\hline
\end{tabular}

WHO: World Health Organization-estimated incidence of TB, 2016; NA: not applicable.

important variable for choosing the first-line biologic therapy. Current recommendations suggest anti-TNFs as the first-line therapy for RA $[188,189]$, but TB reactivation risk should be taken into account by clinicians, and in the case of LTBI diagnosis, a non-anti-TNF- $\alpha$-targeted biologic would probably represent the best choice in terms of efficacy and safety. Other variables should guide the choice among TCZ, ABA, and RTX, including the need for monotherapy, anticitrullinated protein antibodies positivity, and preferred administration route by the patient [190].

The 2015 updated Group for Research and Assessment of Psoriasis and Psoriatic Arthritis (GRAPPA) recommendations for the treatment of PsA and psoriasis include UTK (SEK was not approved at the time of publication) among the biological therapies and consider several variables driving the choice toward an anti-TNF- $\alpha$ as firstline therapy [191]. However, among the considered variables, the authors did not include the possibility of patients with a diagnosis of LTBI. As previously stated in this paper, based on the absence of evidence of an increased TB reactivation risk in patients with PsA receiving UTK or SCK, we suggest to use these non-anti-TNF-targeted biologics as first-line therapy in PsA patients with LTBI.

The same is true for AS treatment. Despite the recent SCK approval, current guidelines recommend anti-TNF as the only choice to treat AS patients with active disease [192, 193] independently on LTBI screening procedures. Nowadays, in our opinion, considering the efficacy and safety of IL-17 inhibition, AS patients with positive LTBI tests should be treated with SCK as first-line biologic.

\section{Conclusion}

The availability of non-anti-TNF-targeted biologics has widened the therapeutic strategies in patients with RA, PsA, and AS, allowing optimization in the biologic choice of function of several clinical variables. Among these, the TB reactivation risk should be assessed in all patients, and in case of positive results, non-anti-TNF- $\alpha$-targeted biologics for RA, UTK, or SCK for PsA, and SCK for AS represent the safest option.

\section{Conflicts of Interest}

The authors declare no conflicts of interest.

\section{References}

[1] F. Cantini, L. Niccoli, and D. Goletti, "Adalimumab, etanercept, infliximab, and the risk of tuberculosis: data from clinical trials, national registries, and postmarketing surveillance," The Journal of Rheumatology. Supplement, vol. 91, pp. 47-55, 2014.

[2] A. Souto, J. R. Maneiro, E. Salgado, L. Carmona, and J. J. Gomez-Reino, "Risk of tuberculosis in patients with chronic immune-mediated inflammatory diseases treated with biologics and tofacitinib: a systematic review and meta-analysis of randomized controlled trials and long-term extension studies," Rheumatology (Oxford), vol. 53, no. 10, pp. 18721885, 2014.

[3] F. Cantini, C. Nannini, L. Niccoli et al., "Guidance for the management of patients with latent tuberculosis infection requiring biologic therapy in rheumatology and dermatology clinical practice," Autoimmunity Reviews, vol. 14, no. 6, pp. 503-509, 2015.

[4] S. Minozzi, S. Bonovas, T. Lytras et al., "Risk of infections using anti-TNF agents in rheumatoid arthritis, psoriatic arthritis, and ankylosing spondylitis: a systematic review and meta-analysis," Expert Opinion on Drug Safety, vol. 15, no. Supplement 1, pp. 11-34, 2016.

[5] F. Cantini, L. Niccoli, and D. Goletti, "Tuberculosis risk in patients treated with non-anti-tumor necrosis factor- $\alpha$ (TNF- $\alpha$ ) targeted biologics and recently licensed TNF- $\alpha$ inhibitors: data from clinical trials and national registries," The Journal of Rheumatology. Supplement, vol. 91, pp. 5664, 2014.

[6] WHO, “Global Tuberculosis report 2015," http://www.who. int/tb/publications/global_report/en/.

[7] D. Falzon, H. J. Schünemann, E. Harausz et al., "WHO treatment guidelines for drug-resistant tuberculosis, 2016 update," European Respiratory Journal, vol. 49, no. 3, article 1602308, 2017.

[8] D. Goletti, E. Petruccioli, S. A. Joosten, and T. H. Ottenhoff, "Tuberculosis biomarkers: from diagnosis to protection," Infectious Disease Reports, vol. 8, no. 2, p. 6568, 2016. 
[9] M. Dara, I. Solovic, G. Sotgiu et al., "Tuberculosis care among refugees arriving in Europe: a ERS/WHO Europe Region survey of current practices," The European Respiratory Journal, vol. 48, no. 3, pp. 808-817, 2016.

[10] K. Lönnroth, G. B. Migliori, I. Abubakar et al., “Towards tuberculosis elimination: an action framework for lowincidence countries," The European Respiratory Journal, vol. 45, no. 4, pp. 928-952, 2015.

[11] M. Raviglione and G. Sulis, "Tuberculosis 2015: burden, challenges and strategy for control and elimination," Infectious Disease Reports, vol. 8, no. 2, p. 6570, 2016.

[12] E. Petruccioli, T. J. Scriba, L. Petrone et al., "Correlates of tuberculosis risk: predictive biomarkers for progression to active tuberculosis," The European Respiratory Journal, vol. 48, no. 6, pp. 1751-1763, 2016.

[13] U. Mack, G. B. Migliori, M. Sester et al., "LTBI: latent tuberculosis infection or lasting immune responses to M. tuberculosis? A TBNET consensus statement," The European Respiratory Journal, vol. 33, no. 5, pp. 956-973, 2009.

[14] S. Gagneux, K. DeRiemer, T. Van et al., "Variable hostpathogen compatibility in Mycobacterium tuberculosis," Proceedings of the National Academy of Sciences of the United States of America, vol. 103, no. 8, pp. 2869-2873, 2006.

[15] D. Brites and S. Gagneux, "Co-evolution of Mycobacterium tuberculosis and Homo sapiens," Immunological Reviews, vol. 264, no. 1, pp. 6-24, 2015.

[16] R. M. Houben and P. J. Dodd, "The global burden of latent tuberculosis infection: a re-estimation using mathematical modelling," PLoS Medicine, vol. 13, no. 10, article e1002152, 2016

[17] C. E. Barry 3rd, H. I. Boshoff, V. Dartois et al., "The spectrum of latent tuberculosis: rethinking the biology and intervention strategies," Nature Reviews. Microbiology, vol. 7, no. 12, pp. 845-855, 2009.

[18] H. Esmail, C. E. Barry 3rd, D. B. Young, and R. J. Wilkinson, "The ongoing challenge of latent tuberculosis," Philosophical Transactions of the Royal Society of London. Series B, Biological Sciences, vol. 369, no. 1645, p. 20130437, 2014.

[19] G. Delogu and D. Goletti, "The spectrum of tuberculosis infection: new perspectives in the era of biologics," The Journal of Rheumatology. Supplement, vol. 91, pp. 11-16, 2014.

[20] A. A. Chackerian, J. M. Alt, T. V. Perera, C. C. Dascher, and S. M. Behar, "Dissemination of Mycobacterium tuberculosis is influenced by host factors and precedes the initiation of T-cell immunity," Infection and Immunity, vol. 70, no. 8, pp. 4501-4509, 2002.

[21] A. J. Wolf, B. Linas, G. J. Trevejo-Nuñez et al., "Mycobacterium tuberculosis infects dendritic cells with high frequency and impairs their function in vivo," Journal of Immunology, vol. 179, no. 4, pp. 2509-2519, 2007.

[22] W. L. Chan, A. Rodgers, R. D. Hancock et al., "Protection in simian immunodeficiency virus-vaccinated monkeys correlates with anti-HLA class I antibody response," The Journal of Experimental Medicine, vol. 176, no. 4, pp. 1203-1207, 1992.

[23] H. S. Choi, P. R. Rai, H. W. Chu, C. Cool, and E. D. Chan, "Analysis of nitric oxide synthase and nitrotyrosine expression in human pulmonary tuberculosis," American Journal of Respiratory and Critical Care Medicine, vol. 166, no. 2, pp. 178-186, 2002.
[24] M. G. Gutierrez, D. B. Munafó, W. Berón, and M. I. Colombo, "Rab7 is required for the normal progression of the autophagic pathway in mammalian cells," Journal of Cell Science, vol. 117, no. Part 13, pp. 2687-2697, 2004.

[25] D. Goletti, E. Petruccioli, A. Romagnoli, M. Piacentini, and G. M. Fimia, "Autophagy in Mycobacterium tuberculosis infection: a passepartout to flush the intruder out?" Cytokine \& Growth Factor Reviews, vol. 24, no. 4, pp. 335-343, 2013.

[26] E. Petruccioli, A. Romagnoli, M. Corazzari et al., "Specific T cells restore the autophagic flux inhibited by Mycobacterium tuberculosis in human primary macrophages," The Journal of Infectious Diseases, vol. 205, no. 9, pp. 1425-1435, 2012.

[27] J. L. Casanova and L. Abel, "Genetic dissection of immunity to mycobacteria: the human model," Annual Review of Immunology, vol. 20, no. 1, pp. 581-620, 2002.

[28] S. A. Khader, G. K. Bell, J. E. Pearl et al., "IL-23 and IL-17 in the establishment of protective pulmonary $\mathrm{CD}^{+} \mathrm{T}$ cell responses after vaccination and during Mycobacterium tuberculosis challenge," Nature Immunology, vol. 8, no. 4, pp. 369377, 2007.

[29] R. Gopal, L. Monin, S. Slight et al., "Unexpected role for IL-17 in protective immunity against hypervirulent Mycobacterium tuberculosis HN878 infection," PLoS Pathogens, vol. 10, no. 5, article e10e04099, 2014.

[30] A. Cruz, A. G. Fraga, J. J. Fountain et al., "Pathological role of interleukin 17 in mice subjected to repeated BCG vaccination after infection with Mycobacterium tuberculosis," The Journal of Experimental Medicine, vol. 207, no. 8, pp. 1609-1616, 2010.

[31] T. M. Wozniak, B. M. Saunders, A. A. Ryan, and W. J. Britton, "Mycobacterium bovis BCG-specific Th17 cells confer partial protection against Mycobacterium tuberculosis infection in the absence of gamma interferon," Infection and Immunity, vol. 78, no. 10, pp. 4187-4194, 2010.

[32] B. Nandi and S. M. Behar, "Regulation of neutrophils by interferon- $\gamma$ limits lung inflammation during tuberculosis infection," The Journal of Experimental Medicine, vol. 208, no. 11, pp. 2251-2262, 2011.

[33] C. Nunes-Alves, M. G. Booty, S. M. Carpenter, P. Jayaraman, A. C. Rothchild, and S. M. Behar, "In search of a new paradigm for protective immunity to TB," Nature Reviews. Microbiology, vol. 12, no. 4, pp. 289-299, 2014.

[34] M. V. da Silva, A. A. Figueiredo, J. R. Machado et al., "T cell activation and proinflammatory cytokine production in clinically cured tuberculosis are time-dependent and accompanied by upregulation of IL-10," PloS One, vol. 8, no. 6, article e65492, 2013.

[35] J. L. Flynn, M. M. Goldstein, J. Chan et al., "Tumor necrosis factor- $\alpha$ is required in the protective immune response against Mycobacterium tuberculosis in mice," Immunity, vol. 2, no. 6, pp. 561-572, 1995.

[36] A. G. Bean, D. R. Roach, H. Briscoe et al., "Structural deficiencies in granuloma formation in TNF gene-targeted mice underlie the heightened susceptibility to aerosol Mycobacterium tuberculosis infection, which is not compensated for by lymphotoxin," Journal of Immunology, vol. 162, no. 6, pp. 3504-3511, 1999.

[37] V. P. Mohan, C. A. Scanga, K. Yu et al., "Effects of tumor necrosis factor alpha on host immune response in chronic persistent tuberculosis: possible role for limiting pathology," Infection and Immunity, vol. 69, no. 3, pp. 1847-1855, 2001. 
[38] J. L. Flynn and J. Chan, "What's good for the host is good for the bug," Trends in Microbiology, vol. 13, no. 3, pp. 98-102, 2005.

[39] J. Harris and J. Keane, "How tumour necrosis factor blockers interfere with tuberculosis immunity," Clinical and Experimental Immunology, vol. 161, no. 1, pp. 1-9, 2010.

[40] P. Jayaraman, I. Sada-Ovalle, T. Nishimura et al., "IL-1 $\beta$ promotes antimicrobial immunity in macrophages by regulating TNFR signaling and caspase-3 activation," Journal of Immunology, vol. 190, no. 8, pp. 4196-4204, 2013.

[41] K. D. Mayer-Barber and A. Sher, "Cytokine and lipid mediator networks in tuberculosis," Immunological Reviews, vol. 264, no. 1, pp. 264-275, 2015.

[42] C. Manca, L. Tsenova, S. Freeman et al., "Hypervirulent M. tuberculosis W/Beijing strains upregulate type I IFNs and increase expression of negative regulators of the JakStat pathway," Journal of Interferon \& Cytokine Research, vol. 25, no. 11, pp. 694-701, 2005.

[43] C. Manca, L. Tsenova, A. Bergtold et al., "Virulence of a Mycobacterium tuberculosis clinical isolate in mice is determined by failure to induce Th1 type immunity and is associated with induction of IFN- $\alpha / \beta$," Proceedings of the National Academy of Sciences of the United States of America, vol. 98, no. 10, pp. 5752-5757, 2001.

[44] T. J. Scriba, B. Kalsdorf, D. A. Abrahams et al., "Distinct, specific IL-17- and IL-22-producing $\mathrm{CD} 4^{+} \mathrm{T}$ cell subsets contribute to the human anti-mycobacterial immune response," Journal of Immunology, vol. 180, no. 3, pp. 1962-1970, 2008.

[45] R. Schindler, J. A. Gelfand, and C. A. Dinarello, "Recombinant C5a stimulates transcription rather than translation of interleukin-1 (IL-1) and tumor necrosis factor: translational signal provided by lipopolysaccharide or IL-1 itself," Blood, vol. 76, no. 8, pp. 1631-1638, 1990.

[46] C. H. Ladel, C. Blum, A. Dreher, K. Reifenberg, M. Kopf, and S. H. Kaufmann, "Lethal tuberculosis in interleukin6-deficient mutant mice," Infection and Immunity, vol. 65, no. 11, pp. 4843-4849, 1997.

[47] P. A. Selwyn, D. Hartel, V. A. Lewis et al., "A prospective study of the risk of tuberculosis among intravenous drug users with human immunodeficiency virus infection," The New England Journal of Medicine, vol. 320, no. 9, pp. 545-550, 1989.

[48] F. Cantini, E. Lubrano, A. Marchesoni et al., "Latent tuberculosis infection detection and active tuberculosis prevention in patients receiving anti-TNF therapy: an Italian nationwide survey," International Journal of Rheumatic Diseases, vol. 19, no. 8, pp. 799-805, 2016.

[49] I. Solovic, M. Sester, J. J. Gomez-Reino et al., “The risk of tuberculosis related to tumour necrosis factor antagonist therapies: a TBNET consensus statement," The European Respiratory Journal, vol. 36, no. 5, pp. 1185-1206, 2010.

[50] D. Bumbacea, S. M. Arend, F. Eyuboglu et al., "The risk of tuberculosis in transplant candidates and recipients: a TBNET consensus statement," The European Respiratory Journal, vol. 40, no. 4, pp. 990-1013, 2012.

[51] A. D. Harries, A. M. Kumar, S. Satyanarayana et al., "Addressing diabetes mellitus as part of the strategy for ending TB," Transactions of the Royal Society of Tropical Medicine and Hygiene, vol. 110, no. 3, pp. 173-179, 2016.
[52] K. Ronacher, S. A. Joosten, R. van Crevel, H. M. Dockrell, G. Walzl, and T. H. Ottenhoff, "Acquired immunodeficiencies and tuberculosis: focus on HIV/AIDS and diabetes mellitus," Immunological Reviews, vol. 264, no. 1, pp. 121-137, 2015.

[53] D. Goletti, A. Sanduzzi, and G. Delogu, "Performance of the tuberculin skin test and interferon-gamma release assays: an update on the accuracy, cutoff stratification, and new potential immune-based approaches," The Journal of Rheumatology. Supplement, vol. 91, pp. 24-31, 2014.

[54] G. G. Mahairas, P. J. Sabo, M. J. Hickey, D. C. Singh, and C. K. Stover, "Molecular analysis of genetic differences between Mycobacterium bovis BCG and virulent M. bovis," Journal of Bacteriology, vol. 178, no. 5, pp. 1274-1282, 1996.

[55] N. C. Gey van Pittius, S. L. Sampson, H. Lee, Y. Kim, P. D. van Helden, and R. M. Warren, "Evolution and expansion of the Mycobacterium tuberculosis PE and PPE multigene families and their association with the duplication of the ESAT-6 (esx) gene cluster regions," BMC Evolutionary Biology, vol. 6, no. 1, p. 95, 2006.

[56] H. S. Whitworth, M. Scott, D. W. Connell, B. Donges, and A. Lalvani, "IGRAs-the gateway to $\mathrm{T}$ cell based TB diagnosis," Methods, vol. 61, no. 1, pp. 52-62, 2013.

[57] P. Andersen, M. E. Munk, J. M. Pollock, and T. M. Doherty, "Specific immune-based diagnosis of tuberculosis," Lancet, vol. 356, no. 9235, pp. 1099-1104, 2000.

[58] “QuantiFERON ${ }^{\circledR}$-TB Gold Plus (QFT ${ }^{\circledR}$-Plus) ELISA package insert," http://www.quantiferon.com/irm/content/PI/QFT/ PLUS/2PK-Elisa/UK.pdf.

[59] T. Mori, M. Sakatani, F. Yamagishi et al., "Specific detection of tuberculosis infection: an interferon-gamma-based assay using new antigens," American Journal of Respiratory and Critical Care Medicine, vol. 170, no. 1, pp. 59-64, 2004.

[60] A. Penn-Nicholson, E. Nemes, W. A. Hanekom, M. Hatherill, and T. J. Scriba, "Mycobacterium tuberculosis-specific CD4 T cells are the principal source of IFN- $\gamma$ in QuantiFERON assays in healthy persons," Tuberculosis (Edinburgh, Scotland), vol. 95, no. 3, pp. 350-351, 2015.

[61] E. Petruccioli, T. Chiacchio, I. Pepponi et al., "First characterization of the CD4 and CD8 T-cell responses to QuantiFERON-TB Plus," The Journal of Infection, vol. 73, no. 6, pp. 588-597, 2016.

[62] E. Petruccioli, A. Navarra, L. Petrone et al., "Use of several immunological markers to model the probability of active tuberculosis," Diagnostic Microbiology and Infectious Disease, vol. 86, no. 2, pp. 169-171, 2016.

[63] T. Chiacchio, E. Petruccioli, V. Vanini et al., "Polyfunctional T-cells and effector memory phenotype are associated with active TB in HIV-infected patients," The Journal of Infection, vol. 69, no. 6, pp. 533-545, 2014.

[64] C. L. Day, D. A. Abrahams, L. Lerumo et al., "Functional capacity of Mycobacterium tuberculosis-specific $\mathrm{T}$ cell responses in humans is associated with mycobacterial load," Journal of Immunology, vol. 187, no. 5, pp. 2222-2232, 2011.

[65] V. Rozot, A. Patrizia, S. Vigano et al., "Combined use of Mycobacterium tuberculosis-specific CD4 and CD8 T-cell responses is a powerful diagnostic tool of active tuberculosis," Clinical Infectious Diseases, vol. 60, no. 3, pp. 432-437, 2015.

[66] V. Rozot, S. Vigano, J. Mazza-Stalder et al., "Mycobacterium tuberculosis-specific $\mathrm{CD}^{+} \mathrm{T}$ cells are functionally and phenotypically different between latent infection and active 
disease," European Journal of Immunology, vol. 43, no. 6, pp. 1568-1577, 2013.

[67] M. Nikolova, R. Markova, R. Drenska et al., "Antigen-specific CD4- and CD8-positive signatures in different phases of Mycobacterium tuberculosis infection," Diagnostic Microbiology and Infectious Disease, vol. 75, no. 3, pp. 277-281, 2013.

[68] M. R. Nyendak, D. M. Lewinsohn, R. D. Shah et al., "ATS Core Curriculum 2014: part I. Adult pulmonary medicine," Annals of the American Thoracic Society, vol. 11, no. 7, pp. 1136-1144, 2014.

[69] L. Barcellini, E. Borroni, J. Brown et al., "First independent evaluation of QuantiFERON-TB Plus performance," The European Respiratory Journal, vol. 47, no. 5, pp. 1587-1590, 2016.

[70] L. Barcellini, E. Borroni, J. Brown et al., "First evaluation of QuantiFERON-TB Gold Plus performance in contact screening," The European Respiratory Journal, vol. 48, no. 5, pp. 1411-1419, 2016.

[71] L. Yi, Y. Sasaki, H. Nagai et al., "Evaluation of QuantiFERON-TB Gold Plus for detection of Mycobacterium tuberculosis infection in Japan," Scientific Reports, vol. 6, p. 30617, 2016.

[72] H. Hoffmann, K. Avsar, R. Göres, S. C. Mavi, and S. Hofmann-Thiel, "Equal sensitivity of the new generation QuantiFERON-TB Gold Plus in direct comparison with the previous test version QuantiFERON-TB Gold IT," Clinical Microbiology and Infection, vol. 22, no. 8, pp. 701-703, 2016.

[73] H. Aggerbeck, R. Giemza, P. Joshi et al., "Randomised clinical trial investigating the specificity of a novel skin test $(\mathrm{C}-\mathrm{Tb})$ for diagnosis of M. tuberculosis infection," PloS One, vol. 8, no. 5, article e64215, 2013.

[74] K. A. Millington, S. M. Fortune, J. Low et al., "Rv3615c is a highly immunodominant RD1 (region of difference 1)dependent secreted antigen specific for Mycobacterium tuberculosis infection," Proceedings of the National Academy of Sciences of the United States of America, vol. 108, no. 14, pp. 5730-5735, 2011.

[75] J. P. Zellweger, G. Sotgiu, M. Block et al., "Risk assessment of tuberculosis in contacts by IFN-gamma release assays. A Tuberculosis Network European Trials Group Study," American Journal of Respiratory and Critical Care Medicine, vol. 191, no. 10, pp. 1176-1184, 2015.

[76] M. X. Rangaka, K. A. Wilkinson, J. R. Glynn et al., "Predictive value of interferon-gamma release assays for incident active tuberculosis: a systematic review and meta-analysis," The Lancet Infectious Diseases, vol. 12, no. 1, pp. 45-55, 2012.

[77] D. E. Zak, A. Penn-Nicholson, T. J. Scriba et al., “A blood RNA signature for tuberculosis disease risk: a prospective cohort study," Lancet, vol. 387, no. 10035, pp. 2312-2322, 2016.

[78] R. Sloot, M. F. van der Loeff, E. W. van Zwet et al., "Biomarkers can identify pulmonary tuberculosis in HIVinfected drug users months prior to clinical diagnosis," eBioMedicine, vol. 2, no. 2, pp. 172-179, 2014.

[79] H. A. Fletcher, M. A. Snowden, B. Landry et al., "T-cell activation is an immune correlate of risk in BCG vaccinated infants," Nature Communications, vol. 7, p. 11290, 2016.

[80] H. A. Fletcher and L. Schrager, "TB vaccine development and the end TB strategy: importance and current status," Transactions of the Royal Society of Tropical Medicine and Hygiene, vol. 110, no. 4, pp. 212-218, 2016.
[81] E. Petruccioli, L. Petrone, V. Vanini et al., "Assessment of CD27 expression as a tool for active and latent tuberculosis diagnosis," The Journal of Infection, vol. 71, no. 5, pp. 526533, 2015.

[82] D. Portevin, F. Moukambi, P. Clowes et al., “Assessment of the novel T-cell activation marker-tuberculosis assay for diagnosis of active tuberculosis in children: a prospective proof-of-concept study," The Lancet Infectious Diseases, vol. 14, no. 10, pp. 931-938, 2014.

[83] T. Prezzemolo, G. Guggino, M. P. La Manna, D. Di Liberto, F. Dieli, and N. Caccamo, "Functional signatures of human CD4 and CD8 T cell responses to Mycobacterium tuberculosis," Frontiers in Immunology, vol. 5, p. 180, 2014.

[84] G. Delogu, V. Vanini, G. Cuzzi et al., "Lack of response to HBHA in HIV-infected patients with latent tuberculosis infection," Scandinavian Journal of Immunology, vol. 84, no. 6, pp. 344-352, 2016.

[85] N. Nishimoto, K. Yoshizaki, N. Miyasaka et al., "Treatment of rheumatoid arthritis with humanized anti-interleukin-6 receptor antibody: a multicenter, double-blind, placebo controlled trial," Arthritis and Rheumatism, vol. 50, no. 6, pp. 1761-1769, 2004.

[86] R. N. Maini, P. C. Taylor, J. Szechinski et al., "Double-blind randomized controlled clinical trial of the interleukin- 6 receptor antagonist, tocilizumab, in European patients with rheumatoid arthritis who had an incomplete response to methotrexate," Arthritis and Rheumatism, vol. 54, no. 9, pp. 2817-2829, 2006.

[87] N. Nishimoto, J. Hashimoto, N. Miyasaka et al., "Study of active controlled monotherapy used for rheumatoid arthritis, an IL-6 inhibitor (SAMURAI): evidence of clinical and radiographic benefit from an $\mathrm{x}$ ray reader-blinded randomised controlled trial of tocilizumab," Annals of the Rheumatic Diseases, vol. 66, no. 9, pp. 1162-1167, 2007.

[88] J. S. Smolen, A. Beaulieu, A. Rubbert-Roth et al., "Effect of interleukin-6 receptor inhibition with tocilizumab in patients with rheumatoid arthritis (OPTION study): a double-blind, placebo-controlled, randomised trial," Lancet, vol. 371, pp. 987-997, 2008.

[89] P. Emery, E. Keystone, H. P. Tony et al., "IL-6 receptor inhibition with tocilizumab improves treatment outcomes in patients with rheumatoid arthritis refractory to antitumour necrosis factor biologicals: results from a 24 -week multicentre randomised placebo-controlled trial," Annals of the Rheumatic Diseases, vol. 67, no. 11, pp. 1516-1523, 2008.

[90] M. C. Genovese, J. D. McKay, E. L. Nasonov et al., "Interleukin-6 receptor inhibition with tocilizumab reduces disease activity in rheumatoid arthritis with inadequate response to disease-modifying antirheumatic drugs: the tocilizumab in combination with traditional disease-modifying antirheumatic drug therapy study," Arthritis and Rheumatism, vol. 58, no. 10, pp. 2968-2980, 2008.

[91] N. Nishimoto, N. Miyasaka, K. Yamamoto et al., "Study of active controlled tocilizumab monotherapy for rheumatoid arthritis patients with an inadequate response to methotrexate (SATORI): significant reduction in disease activity and serum vascular endothelial growth factor by IL-6 receptor inhibition therapy," Modern Rheumatology, vol. 19, no. 1, pp. 12-19, 2009.

[92] N. Nishimoto, N. Miyasaka, K. Yamamoto, S. Kawai, T. Takeuchi, and J. Azuma, "Long-term safety and efficacy of 
tocilizumab, an anti-IL-6 receptor monoclonal antibody, in monotherapy, in patients with rheumatoid arthritis (the STREAM study): evidence of safety and efficacy in a 5-year extension study," Annals of the Rheumatic Diseases, vol. 68, pp. 1580-1584, 2009.

[93] G. Jones, A. Sebba, J. Gu et al., "Comparison of tocilizumab monotherapy versus methotrexate monotherapy in patients with moderate to severe rheumatoid arthritis: the AMBITION study," Annals of the Rheumatic Diseases, vol. 69, no. 1, pp. 88-96, 2010.

[94] Y. Hirabayashi, T. Ishii, and H. Harigae, "Clinical efficacy of tocilizumab in patients with active rheumatoid arthritis in real clinical practice," Rheumatology International, vol. 30, no. 8, pp. 1041-1048, 2010.

[95] H. Yamanaka, Y. Tanaka, E. Inoue et al., "Efficacy and tolerability of tocilizumab in rheumatoid arthritis patients seen in daily clinical practice in Japan: results from a retrospective study (REACTION study)," Modern Rheumatology, vol. 21, no. 2, pp. 122-133, 2011.

[96] G. R. Burmester, E. Feist, H. Kellner, J. Braun, C. IkingKonert, and A. Rubbert-Roth, "Effectiveness and safety of the interleukin 6-receptor antagonist tocilizumab after 4 and 24 weeks in patients with active rheumatoid arthritis: the first phase IIIb real-life study (TAMARA)," Annals of the Rheumatic Diseases, vol. 70, no. 5, pp. 755-759, 2011.

[97] J. M. Kremer, R. Blanco, M. Brzosko et al., "Tocilizumab inhibits structural joint damage in rheumatoid arthritis patients with inadequate responses to methotrexate: results from the double-blind treatment phase of a randomized placebo-controlled trial of tocilizumab safety and prevention of structural joint damage at one year," Arthritis and Rheumatism, vol. 63, no. 3, pp. 609-621, 2011.

[98] T. Takeuchi, Y. Tanaka, K. Amano et al., "Clinical, radiographic and functional effectiveness of tocilizumab for rheumatoid arthritis patients-REACTION 52-week study," Rheumatology (Oxford), vol. 50, no. 10, pp. 1908-1915, 2011.

[99] K. Kume, K. Amano, S. Yamada, K. Hatta, H. Ohta, and N. Kuwaba, "Tocilizumab monotherapy reduces arterial stiffness as effectively as etanercept or adalimumab monotherapy in rheumatoid arthritis: an open-label randomized controlled trial," The Journal of Rheumatology, vol. 38, no. 10, pp. 2169-2171, 2011.

[100] Y. Yazici, J. R. Curtis, A. Ince et al., "Efficacy of tocilizumab in patients with moderate to severe active rheumatoid arthritis and a previous inadequate response to disease-modifying antirheumatic drugs: the ROSE study," Annals of the Rheumatic Diseases, vol. 71, no. 2, pp. 198-205, 2012.

[101] M. Dougados, K. Kissel, T. Sheeran et al., "Adding tocilizumab or switching to tocilizumab monotherapy in methotrexate inadequate responders: 24-week symptomatic and structural results of a 2-year randomised controlled strategy trial in rheumatoid arthritis (ACT-RAY)," Annals of the Rheumatic Diseases, vol. 72, no. 1, pp. 43-50, 2013.

[102] V. P. Bykerk, A. J. Ostör, J. Alvaro-Gracia et al., “Tocilizumab in patients with active rheumatoid arthritis and inadequate responses to DMARDs and/or TNF inhibitors: a large, open-label study close to clinical practice," Annals of the Rheumatic Diseases, vol. 71, no. 12, pp. 1950-1954, 2012.

[103] V. Strand, G. R. Burmester, S. Ogale, J. Devenport, A. John, and P. Emery, "Improvements in health-related quality of life after treatment with tocilizumab in patients with rheumatoid arthritis refractory to tumour necrosis factor inhibitors: results from the 24-week randomized controlled RADIATE study," Rheumatology (Oxford), vol. 51, no. 10, pp. 18601869, 2012.

[104] C. Gabay, P. Emery, R. van Vollenhoven et al., "Tocilizumab monotherapy versus adalimumab monotherapy for treatment of rheumatoid arthritis (ADACTA): a randomised, double-blind, controlled phase 4 trial," The Lancet, vol. 381, no. 9877, pp. 1541-1550, 2013.

[105] G. R. Burmester, A. Rubbert-Roth, A. Cantagrel et al., "A randomised, double-blind, parallel-group study of the safety and efficacy of subcutaneous tocilizumab versus intravenous tocilizumab in combination with traditional disease-modifying antirheumatic drugs in patients with moderate to severe rheumatoid arthritis (SUMMACTA study)," Annals of the Rheumatic Diseases, vol. 73, no. 1, pp. 69-74, 2014.

[106] A. Ogata, K. Tanimura, T. Sugimoto et al., "Phase III study of the efficacy and safety of subcutaneous versus intravenous tocilizumab monotherapy in patients with rheumatoid arthritis," Arthritis Care \& Research (Hoboken), vol. 66, no. 3, pp. 344-354, 2014.

[107] J. M. Álvaro-Gracia, A. Fernández-Nebro, A. García-López et al., "Tocilizumab in patients with active rheumatoid arthritis and inadequate response to disease-modifying antirheumatic drugs or tumor necrosis factor inhibitors: subanalysis of Spanish results of an open-label study close to clinical practice," Reumatología Clínica, vol. 10, no. 2, pp. 94-100, 2014.

[108] M. Dougados, K. Kissel, P. G. Conaghan et al., "Clinical, radiographic and immunogenic effects after 1 year of tocilizumab-based treatment strategies in rheumatoid arthritis: the ACT-RAY study," Annals of the Rheumatic Diseases, vol. 73, no. 5, pp. 803-809, 2014.

[109] Y. Nakashima, M. Kondo, T. Fukuda et al., "Remission in patients with active rheumatoid arthritis by tocilizumab treatment in routine clinical practice: results from 3 years of prospectively registered data," Modern Rheumatology, vol. 24, no. 2, pp. 258-264, 2014.

[110] A. Kivitz, E. Olech, M. Borofsky et al., "Subcutaneous tocilizumab versus placebo in combination with diseasemodifying antirheumatic drugs in patients with rheumatoid arthritis," Arthritis Care \& Research (Hoboken), vol. 66, no. 11, pp. 1653-1661, 2014.

[111] V. P. Bykerk, A. J. Östör, J. Alvaro-Gracia et al., "Comparison of tocilizumab as monotherapy or with add-on diseasemodifying antirheumatic drugs in patients with rheumatoid arthritis and inadequate responses to previous treatments: an open-label study close to clinical practice," Clinical Rheumatology, vol. 34, no. 3, pp. 563-571, 2015.

[112] G. R. Burmester, A. Rubbert-Roth, A. Cantagrel et al., "Efficacy and safety of subcutaneous tocilizumab versus intravenous tocilizumab in combination with traditional DMARDs in patients with RA at week 97 (SUMMACTA)," Annals of the Rheumatic Diseases, vol. 75, no. 1, pp. 68-74, 2016.

[113] J. M. Kremer, R. Blanco, A. M. Halland et al., "Clinical efficacy and safety maintained up to 5 years in patients with rheumatoid arthritis treated with tocilizumab in a randomised trial," Clinical and Experimental Rheumatology, vol. 34, no. 4, pp. 625-633, 2016.

[114] J. W. Bijlsma, P. M. Welsing, T. G. Woodworth et al., "Early rheumatoid arthritis treated with tocilizumab, methotrexate, or their combination (U-Act-Early): a multicentre, randomised, 
double-blind, double-dummy, strategy trial," Lancet, vol. 388, no. 10042, pp. 343-355, 2016.

[115] R. Sakai, S. K. Cho, T. Nanki et al., "Head-to-head comparison of the safety of tocilizumab and tumor necrosis factor inhibitors in rheumatoid arthritis patients (RA) in clinical practice: results from the registry of Japanese RA patients on biologics for long-term safety (REAL) registry," Arthritis Research \& Therapy, vol. 17, p. 74, 2015.

[116] T. Koike, M. Harigai, S. Inokuma et al., "Postmarketing surveillance of tocilizumab for rheumatoid arthritis in Japan: interim analysis of 3881 patients," Annals of the Rheumatic Diseases, vol. 70, no. 12, pp. 2148-2151, 2011.

[117] World Health Organization Global Tuberculosis Report 2012. WHO Library Cataloguing-in-Publication Data, Information Resource Centre HTM/STB World Health Organization, Geneve, Switzerland, ISBN 9789241564502, http://apps.who .int/iris/bitstream/10665/75938/1/9789241564502_eng.pdf.

[118] M. H. Schiff, J. M. Kremer, A. Jahreis, E. Vernon, J. D. Isaacs, and R. F. van Vollenhoven, "Integrated safety in tocilizumab clinical trials," Arthritis Research \& Therapy, vol. 13, no. 5, p. R141, 2011.

[119] C. O. Bingham III, "Emerging therapeutics for rheumatoid arthritis," Bulletin of the NYU Hospital for Joint Diseases, vol. 66, no. 3, pp. 210-215, 2008.

[120] J. C. Edwards, L. Szczepanski, J. Szechinski et al., "Efficacy of B-cell-targeted therapy with rituximab in patients with rheumatoid arthritis," The New England Journal of Medicine, vol. 350, no. 25, pp. 2572-2581, 2004.

[121] P. J. Mease, D. A. Revicki, J. Szechinski et al., "Improved health-related quality of life for patients with active rheumatoid arthritis receiving rituximab: results of the Dose-Ranging Assessment: International Clinical Evaluation of Rituximab in Rheumatoid Arthritis (DANCER) trial," The Journal of Rheumatology, vol. 35, no. 1, pp. 20-30, 2008.

[122] P. J. Mease, S. Cohen, N. B. Gaylis et al., "Efficacy and safety of retreatment in patients with rheumatoid arthritis with previous inadequate response to tumor necrosis factor inhibitors: results from the SUNRISE trial," The Journal of Rheumatology, vol. 37, no. 5, pp. 917-927, 2010.

[123] P. Emery, R. Fleischmann, A. Filipowicz-Sosnowska et al., "The efficacy and safety of rituximab in patients with active rheumatoid arthritis despite methotrexate treatment: results of a phase IIB randomized, double-blind, placebo-controlled, dose-ranging trial," Arthritis and Rheumatism, vol. 54, no. 5, pp. 1390-1400, 2006.

[124] S. B. Cohen, P. Emery, M. W. Greenwald et al., "Rituximab for rheumatoid arthritis refractory to anti-tumor necrosis factor therapy: results of a multicenter, randomized, double-blind, placebo-controlled, phase III trial evaluating primary efficacy and safety at twenty-four weeks," Arthritis and Rheumatism, vol. 54, no. 9, pp. 2793-2806, 2006.

[125] A. Rubbert-Roth, P. P. Tak, C. Zerbini et al., "Efficacy and safety of various repeat treatment dosing regimens of rituximab in patients with active rheumatoid arthritis: results of a phase III randomized study (MIRROR)," Rheumatology (Oxford), vol. 49, no. 9, pp. 1683-1693, 2010.

[126] P. Emery, A. Deodhar, W. F. Rigby et al., "Efficacy and safety of different doses and retreatment of rituximab: a randomised, placebo-controlled trial in patients who are biological naive with active rheumatoid arthritis and an inadequate response to methotrexate (Study Evaluating Rituximab's
Efficacy in MTX iNadequate rEsponders (SERENE))," Annals of the Rheumatic Diseases, vol. 69, no. 9, pp. 1629$1635,2010$.

[127] M. W. Greenwald, W. J. Shergy, J. L. Kaine, M. T. Sweetser, K. Gilder, and M. D. Linnik, "Evaluation of the safety of rituximab in combination with a tumor necrosis factor inhibitor and methotrexate in patients with active rheumatoid arthritis: results from a randomized controlled trial," Arthritis and Rheumatism, vol. 63, no. 3, pp. 622-632, 2011.

[128] P. P. Tak, W. F. Rigby, A. Rubbert-Roth et al., "Inhibition of joint damage and improved clinical outcomes with rituximab plus methotrexate in early activerheumatoid arthritis: the IMAGE trial," Annals of the Rheumatic Diseases, vol. 70, no. 1, pp. 39-46, 2011.

[129] L. Brulhart, A. Ciurea, A. Finckh et al., "Efficacy of B cell depletion in patients with rheumatoid arthritis refractory to anti-tumour necrosis factor alpha agents: an open-label observational study," Annals of the Rheumatic Diseases, vol. 65, no. 9, pp. 1255-1257, 2006.

[130] R. N. Jois, A. Masding, M. Somerville, K. Gaffney, and D. G. Scott, "Rituximab therapy in patients with resistant rheumatoid arthritis: real-life experience," Rheumatology (Oxford), vol. 46, no. 6, pp. 980-982, 2007.

[131] D. McGonagle, A. L. Tan, J. Madden, L. Taylor, and P. Emery, "Rituximab use in everyday clinical practice as a first-line biologic therapy for the treatment of DMARDresistantrheumatoid arthritis," Rheumatology (Oxford), vol. 47 , no. 6 , pp. 865-867, 2008.

[132] R. M. Thurlings, K. Vos, D. M. Gerlag, and P. P. Tak, "Disease activity-guided rituximab therapy in rheumatoid arthritis: the effects of re-treatment in initial nonresponders versus initial responders," Arthritis and Rheumatism, vol. 58, no. 12, pp. 3657-3664, 2008.

[133] J. Sellam, H. Hendel-Chavez, S. Rouanet et al., "B cell activation biomarkers as predictive factors for the response to rituximab in rheumatoid arthritis: a six-month, national, multicenter, open-label study," Arthritis and Rheumatism, vol. 63, no. 4, pp. 933-938, 2011.

[134] B. Haraoui, M. Bokarewa, I. Kallmeyer, V. P. Bykerk, and R. E. S. E. T. Investigators, "Safety and effectiveness of rituximab in patients with rheumatoid arthritis following an inadequate response to 1 prior tumor necrosis factor inhibitor: the RESET trial," The Journal of Rheumatology, vol. 38, no. 12, pp. 2548-2556, 2011.

[135] J. J. Gomez-Reino, J. R. Maneiro, J. Ruiz et al., "Comparative effectiveness of switching to alternative tumour necrosis factor (TNF) antagonists versus switching to rituximab in patients with rheumatoid arthritis who failed previous TNF antagonists: the MIRAR study," Annals of the Rheumatic Diseases, vol. 71, no. 11, pp. 1861-1864, 2012.

[136] A. Isvy, M. Meunier, C. Gobeaux-Chenevier et al., "Safety of rituximab in rheumatoid arthritis: a long-term prospective single-center study of gammaglobulin concentrations and infections," Joint, Bone, Spine, vol. 79, no. 4, pp. 365-369, 2012.

[137] J. Narvaez, C. Díaz-Torné, J. M. Ruiz et al., "Predictors of response to rituximab in patients with active rheumatoid arthritis and inadequate response to anti-TNF agents or traditional DMARDs," Clinical and Experimental Rheumatology, vol. 29, no. 6, pp. 991-997, 2011.

[138] R. F. van Vollenhoven, P. Emery, C. O. Bingham 3rd et al., "Long-term safety of rituximab in rheumatoid arthritis: 
9.5-year follow-up of the global clinical trial programme with a focus on adverse events of interest in RA patients," Annals of the Rheumatic Diseases, vol. 72, no. 9, pp. 14961502, 2013.

[139] K. L. Winthrop, S. Yamashita, S. E. Beekmann, P. M. Polgreen, and Infectious Diseases Society of America Emerging Infections Network, "Mycobacterial and other serious infections in patients receiving anti-tumor necrosis factor and other newly approved biologic therapies: case finding through the Emerging Infections Network," Clinical Infectious Diseases, vol. 46, no. 11, pp. 1738-1740, 2008.

[140] T. L. Liao, C. H. Lin, Y. M. Chen, C. L. Chang, H. H. Chen, and D. Y. Chen, "Different risk of tuberculosis and efficacy of isoniazid prophylaxis in rheumatoid arthritis patients with biologic therapy: a nationwide retrospective cohort study in Taiwan," PloS One, vol. 11, no. 4, article e0153217, 2016.

[141] S. Ottaviani, J. Tiendrebeogo, L. Choudat et al., "Knee tuberculosis under rituximab therapy for rheumatoid arthritis," Joint, Bone, Spine, vol. 80, no. 4, pp. 435-436, 2012.

[142] J. E. Gottenberg, P. Ravaud, T. Bardin et al., "Risk factors for severe infections in patients with rheumatoid arthritis treated with rituximab in the autoimmunity and rituximab registry," Arthritis and Rheumatism, vol. 62, no. 9, pp. 2625-2632, 2010.

[143] H. P. Tony, G. Burmester, H. Schulze-Koops et al., "Safety and clinical outcomes of rituximab therapy in patients with different autoimmune diseases: experience from a national registry (GRAID)," Arthritis Research \& Therapy, vol. 13, no. 13, p. R75, 2011.

[144] D. Vassilopoulos, E. M. Delicha, L. Settas et al., "Safety profile of repeated rituximab cycles in unselected rheumatoid arthritis patients: a long-term, prospective real-life study," Clinical and Experimental Rheumatology, vol. 34, no. 5, pp. 893-900, 2016.

[145] J. Wendler, G. R. Burmester, H. Sörensen et al., "Rituximab in patients with rheumatoid arthritis in routine practice (GERINIS): six-year results from a prospective, multicentre, noninterventional study in 2,484 patients," Arthritis Research \& Therapy, vol. 16, no. 2, p. R80, 2014.

[146] Y. M. Chen, H. H. Chen, K. L. Lai, W. T. Hung, J. L. Lan, and D. Y. Chen, "The effects of rituximab therapy on released interferon- $\gamma$ levels in the QuantiFERON assay among RA patients with different status of Mycobacterium tuberculosis infection," Rheumatology (Oxford), vol. 52, no. 4, pp. 697704, 2013.

[147] Y. Pehlivan, B. Kisacik, V. K. Bosnak, and A. M. Onat, "Rituximab seems to be a safer alternative in patients with active rheumatoid arthritis with tuberculosis," BML Case Reports, vol. 2013, 2013.

[148] P. Xanthouli, S. Sailer, and C. Fiehn, "Rituximab (RTX) as an alternative to TNF-alpha antagonists in patients with rheumatoid arthritis and high risk of severe infections: a systematic analysis of the experience in one center," The Open Rheumatology Journal, vol. 6, pp. 286-289, 2012.

[149] M. H. Buch, J. S. Smolen, N. Betteridge et al., "Updated consensus statement on the use of rituximab in patients with rheumatoid arthritis," Annals of the Rheumatic Diseases, vol. 70, no. 6, pp. 909-920, 2011.

[150] L. W. Moreland, R. Alten, F. Van den Bosch et al., "Costimulatory blockade in patients with rheumatoid arthritis: a pilot, dose-finding, double-blind, placebo-controlled clinical trial evaluating CTLA-4Ig and LEA29Y eighty-five days after the first infusion," Arthritis and Rheumatism, vol. 46, no. 6 , pp. 1470-1479, 2002

[151] G. Bernal-Fernandez, P. Espinosa-Cueto, R. Leyva-Meza, N. Mancilla, and R. Mancilla, "Decreased expression of T-cell costimulatory molecule CD28 on CD4 and CD8 T cells of Mexican patients with pulmonary tuberculosis," Tuberculosis Research and Treatment, vol. 2010, Article ID 517547, 8 pages, 2010.

[152] J. M. Kremer, R. Westhovens, M. Leon et al., "Treatment of rheumatoid arthritis by selective inhibition of T-cell activation with fusion protein CTLA4Ig," The New England Journal of Medicine, vol. 349, no. 20, pp. 1907-1915, 2003.

[153] J. M. Kremer, M. Dougados, P. Emery et al., "Treatment of rheumatoid arthritis with the selective costimulation modulator abatacept: twelve-month results of a phase iib, doubleblind, randomized, placebo-controlled trial," Arthritis and Rheumatism, vol. 52, no. 10, pp. 2263-2271, 2005.

[154] M. C. Genovese, J. C. Becker, M. Schiff et al., "Abatacept for rheumatoid arthritis refractory to tumor necrosis factor alpha inhibition," The New England Journal of Medicine, vol. 353, no. 11, pp. 1114-1123, 2005.

[155] R. Westhovens, J. C. Cole, T. Li et al., "Improved healthrelated quality of life for rheumatoid arthritis patients treated with abatacept who have inadequate response to anti-TNF therapy in a double-blind, placebo-controlled, multicentre randomized clinical trial," Rheumatology (Oxford), vol. 45, no. 10, pp. 1238-1246, 2006.

[156] P. Emery, M. Kosinski, T. Li et al., "Treatment of rheumatoid arthritis patients with abatacept and methotrexate significantly improved health-related quality of life," The Journal of Rheumatology, vol. 33, no. 4, pp. 681-689, 2006.

[157] J. M. Kremer, H. K. Genant, L. W. Moreland et al., "Effects of abatacept in patients with methotrexate-resistant active rheumatoid arthritis: a randomized trial," Annals of Internal Medicine, vol. 144, no. 12, pp. 865-876, 2006.

[158] M. Weinblatt, M. Schiff, A. Goldman et al., "Selective costimulation modulation using abatacept in patients with active rheumatoid arthritis while receiving etanercept: a randomised clinical trial," Annals of the Rheumatic Diseases, vol. 66, no. 2, pp. 228-234, 2007.

[159] M. Weinblatt, B. Combe, A. Covucci, R. Aranda, J. C. Becker, and E. Keystone, "Safety of the selective costimulation modulator abatacept in rheumatoid arthritis patients receiving background biologic and nonbiologic disease-modifying antirheumatic drugs: a one-year randomized, placebocontrolled study," Arthritis and Rheumatism, vol. 54, no. 9, pp. 2807-2816, 2006.

[160] M. Schiff, M. Keiserman, C. Codding et al., "Efficacy and safety of abatacept or infliximab vs placebo in ATTEST: a phase III, multi-centre, randomised, double-blind, placebo-controlled study in patients with rheumatoid arthritis and an inadequate response to methotrexate," Annals of the Rheumatic Diseases, vol. 67, no. 8, pp. 1096-1103, 2008.

[161] M. Schiff, C. Pritchard, J. E. Huffstutter et al., "The 6-month safety and efficacy of abatacept in patients with rheumatoid arthritis who underwent a washout after anti-tumour necrosis factor therapy or were directly switched to abatacept: the ARRIVE trial," Annals of the Rheumatic Diseases, vol. 68, no. 11, pp. 1708-1714, 2009.

[162] R. Westhovens, M. Robles, A. C. Ximenes et al., "Clinical efficacy and safety of abatacept in methotrexate-naive 
patients with early rheumatoid arthritis and poor prognostic factors," Annals of the Rheumatic Diseases, vol. 68, no. 12, pp. 1870-1877, 2009.

[163] P. Emery, P. Durez, M. Dougados et al., "Impact of T-cell costimulation modulation in patients with undifferentiated inflammatory arthritis or very early rheumatoid arthritis: a clinical and imaging study of abatacept (the ADJUST trial)," Annals of the Rheumatic Diseases, vol. 69, no. 3, pp. 510516, 2010.

[164] M. C. Genovese, A. Covarrubias, G. Leon et al., "Subcutaneous abatacept versus intravenous abatacept: a phase IIIb noninferiority study in patients with an inadequate response to methotrexate," Arthritis and Rheumatism, vol. 63, no. 10, pp. 2854-2864, 2011.

[165] E. C. Keystone, J. M. Kremer, A. Russell et al., "Abatacept in subjects who switch from intravenous to subcutaneous therapy: results from the phase IIIb ATTUNE study," Annals of the Rheumatic Diseases, vol. 71, no. 6, pp. 857-861, 2012.

[166] M. Schiff, M. E. Weinblatt, R. Valente et al., "Head-to-head comparison of subcutaneous abatacept versus adalimumab for rheumatoid arthritis: two-year efficacy and safety findings from AMPLE trial," Annals of the Rheumatic Diseases, vol. 73, no. 1, pp. 86-94, 2014.

[167] P. Emery, G. R. Burmester, V. P. Bykerk et al., "Evaluating drug-free remission with abatacept in early rheumatoid arthritis: results from the phase $3 \mathrm{~b}$, multicentre, randomised, active-controlled AVERT study of 24 months, with a 12-month, double-blind treatment period," Annals of the Rheumatic Diseases, vol. 74, no. 1, pp. 19-26, 2015.

[168] J. M. Kremer, A. S. Russell, P. Emery et al., "Long-term safety, efficacy and inhibition of radiographic progression with abatacept treatment in patients with rheumatoid arthritis and an inadequate response to methotrexate: 3-year results from the AIM trial," Annals of the Rheumatic Diseases, vol. 70, no. 10, pp. 1826-1830, 2011.

[169] J. M. Kremer, C. Peterfy, A. S. Russell et al., "Longterm safety, efficacy, and inhibition of structural damage progression over 5 years of treatment with abatacept in patients with rheumatoid arthritis in the abatacept in inadequate responders to methotrexate trial," The Journal of Rheumatology, vol. 41, no. 6, pp. 1077-1087, 2014.

[170] R. Westhovens, J. M. Kremer, P. Emery et al., "Long-term safety and efficacy of abatacept in patients with rheumatoid arthritis and an inadequate response to methotrexate: a 7year extended study," Clinical and Experimental Rheumatology, vol. 32, no. 4, pp. 553-562, 2014.

[171] X. Mariette, J. E. Gottenberg, P. Ravaud, and B. Combe, "Registries in rheumatoid arthritis and autoimmune diseases: data from the French registries," Rheumatology (Oxford), vol. 50, pp. 222-229, 2011.

[172] N. Takahashi, T. Kojima, A. Kaneko et al., "Longterm efficacy and safety of abatacept in patients with rheumatoid arthritis treated in routine clinical practice: effect of concomitant methotrexate after 24 weeks," The Journal of Rheumatology, vol. 42, no. 5, pp. 786-793, 2015.

[173] M. Montepaone, E. Lubrano, A. Carboni, and A. Spadaro, "Profile of ustekinumab and its potential in the treatment of active psoriatic arthritis," Open Access Rheumatology: Research and Reviews, vol. 6, pp. 7-13, 2014.

[174] J. Leipe, M. Grunke, C. Dechant et al., "Role of Th17 cells in human autoimmune arthritis," Arthritis and Rheumatism, vol. 62 , no. 10 , pp. 2876-2885, 2010.
[175] A. Gottlieb, A. Menter, A. Mendelsohn et al., "Ustekinumab, a human interleukin 12/23 monoclonal antibody, for psoriatic arthritis: randomised, double-blind, placebo-controlled, crossover trial," Lancet, vol. 373, no. 9664, pp. 633-640, 2009.

[176] I. B. McInnes, A. Kavanaugh, A. B. Gottlieb et al., "Efficacy and safety of ustekinumab in patients with active psoriatic arthritis: 1 year results of the phase 3, multicentre, doubleblind, placebo-controlled PSUMMIT 1 trial," Lancet, vol. 382, no. 9894, pp. 780-789, 2013.

[177] C. Ritchlin, P. Rahman, A. Kavanaugh et al., "Efficacy and safety of the anti-IL-12/23 p40 monoclonal antibody, ustekinumab, in patients with active psoriatic arthritis despite conventional non-biological and biological anti-tumour necrosis factor therapy: 6-month and 1-year results of the phase 3, multicentre, double-blind, placebo-controlled, randomised PSUMMIT 2 trial," Annals of the Rheumatic Diseases, vol. 73, no. 6, pp. 990-999, 2014.

[178] A. Kavanaugh, L. Puig, A. B. Gottlieb et al., "Maintenance of clinical efficacy and radiographic benefit through two years of ustekinumab therapy in patients with active psoriatic arthritis: results from a randomized, placebo-controlled phase III trial," Arthritis Care \& Research (Hoboken), vol. 67, no. 12, pp. 1739-1749, 2015.

[179] T. F. Tsai, V. Ho, M. Song et al., "The safety of ustekinumab treatment in patients with moderate-to-severe psoriasis and latent tuberculosis infection," The British Journal of Dermatology, vol. 167, no. 5, pp. 1145-1152, 2012.

[180] R. E. Kalb, D. F. Fiorentino, M. G. Lebwohl et al., "Risk of serious infection with biologic and systemic treatment of psoriasis: results from the Psoriasis Longitudinal Assessment and Registry (PSOLAR)," JAMA Dermatology, vol. 151, no. 9, pp. 961-969, 2015.

[181] I. B. McInnes, J. Sieper, J. Braun et al., "Efficacy and safety of secukinumab, a fully human anti-interleukin-17A monoclonal antibody, in patients with moderate-to-severe psoriatic arthritis: a 24-week, randomised, double-blind, placebo-controlled, phase II proof-of-concept trial," Annals of the Rheumatic Diseases, vol. 73, no. 2, pp. 349-356, 2014.

[182] I. B. McInnes, P. J. Mease, B. Kirkham et al., "Secukinumab, a human anti-interleukin-17A monoclonal antibody, in patients with psoriatic arthritis (FUTURE 2): a randomised, double-blind, placebo-controlled, phase 3 trial," Lancet, vol. 386, no. 9999, pp. 1137-1146, 2015.

[183] P. J. Mease, I. B. McInnes, B. Kirkham et al., "Secukinumab inhibition of interleukin-17A in patients with psoriatic arthritis," The New England Journal of Medicine, vol. 373, no. 14, pp. 1329-1339, 2015.

[184] D. Baeten, X. Baraliakos, J. Braun et al., “Anti-interleukin-17A monoclonal antibody secukinumab in treatment of ankylosing spondylitis: a randomised, double-blind, placebo-controlled trial," Lancet, vol. 382, no. 9906, pp. 1705-1713, 2013.

[185] D. Baeten, J. Sieper, J. Braun et al., "Secukinumab, an interleukin-17A inhibitor, in ankylosing spondylitis," The New England Journal of Medicine, vol. 373, no. 26, pp. 2534-2548, 2015.

[186] A. Blauvelt, "Safety of secukinumab in the treatment of psoriasis," Expert Opinion on Drug Safety, vol. 15, no. 10, pp. 1413-1420, 2016.

[187] F. Cantini and D. Goletti, "Biologics and tuberculosis risk: the rise and fall of an old disease and its new resurgence," The Journal of Rheumatology. Supplement, vol. 91, pp. 1-3, 2014. 
[188] J. A. Singh, D. E. Furst, A. Bharat et al., "2012 update of the 2008 American College of Rheumatology recommendations for the use of disease-modifying antirheumatic drugs and biologic agents in the treatment of rheumatoid arthritis," Arthritis Care \& Research (Hoboken), vol. 64, no. 5, pp. 625-639, 2012.

[189] J. S. Smolen, R. Landewé, F. C. Breedveld et al., "EULAR recommendations for the management of rheumatoid arthritis with synthetic and biological disease-modifying antirheumatic drugs: 2013 update," Annals of the Rheumatic Diseases, vol. 73, no. 3, pp. 492-509, 2014.

[190] F. Cantini, L. Niccoli, C. Nannini et al., "Tailored first-line biologic therapy in patients with rheumatoid arthritis, spondyloarthritis, and psoriatic arthritis," Seminars in Arthritis and Rheumatism, vol. 45, no. 5, pp. 519-532, 2016.

[191] L. C. Coates, A. Kavanaugh, P. J. Mease et al., "Group for research and assessment of psoriasis and psoriatic arthritis 2015 treatment recommendations for psoriatic arthritis," Arthritis \& Rhematology, vol. 68, no. 5, pp. 10601071, 2016.

[192] M. M. Ward, A. Deodhar, E. A. Akl et al., "American College of Rheumatology/Spondylitis Association of America/ Spondyloarthritis Research and Treatment Network 2015 recommendations for the treatment of ankylosing spondylitis and nonradiographic axial spondyloarthritis," Arthritis \& Rhematology, vol. 68, no. 2, pp. 282-298, 2016.

[193] J. Braun, R. van den Berg, X. Baraliakos et al., "2010 update of the ASAS/EULAR recommendations for the management of ankylosing spondylitis," Annals of the Rheumatic Diseases, vol. 70, no. 6, pp. 896-904, 2011. 


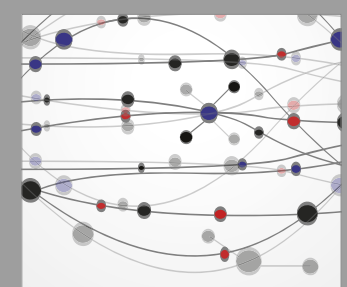

The Scientific World Journal
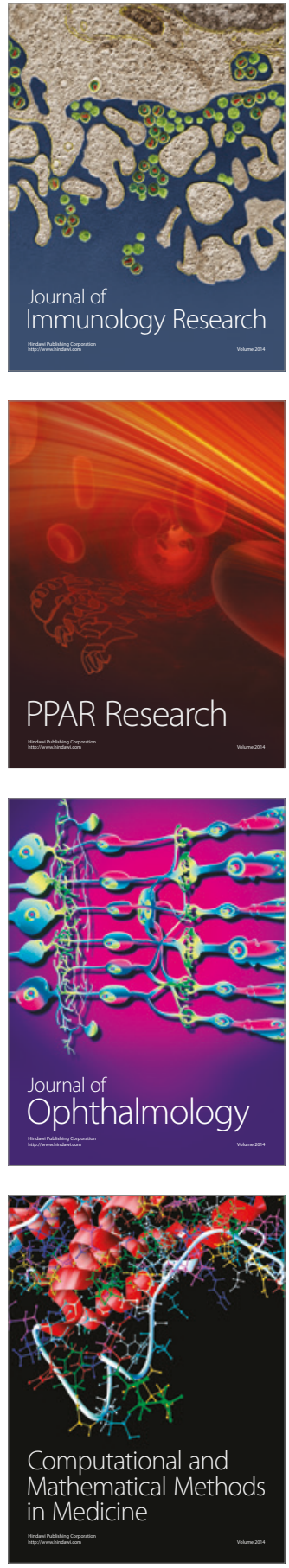

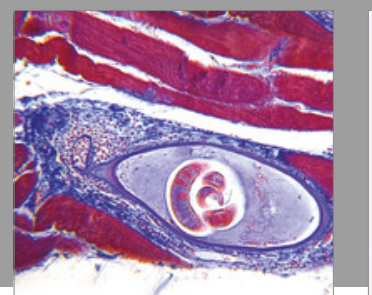

Gastroenterology Research and Practice
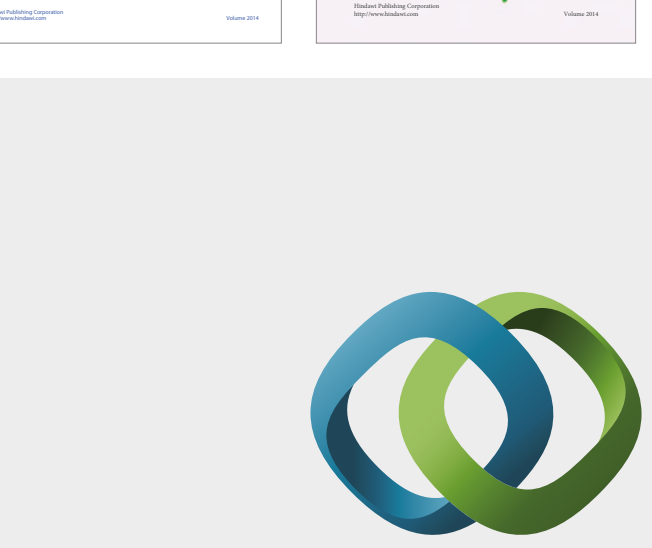

\section{Hindawi}

Submit your manuscripts at

https://www.hindawi.com
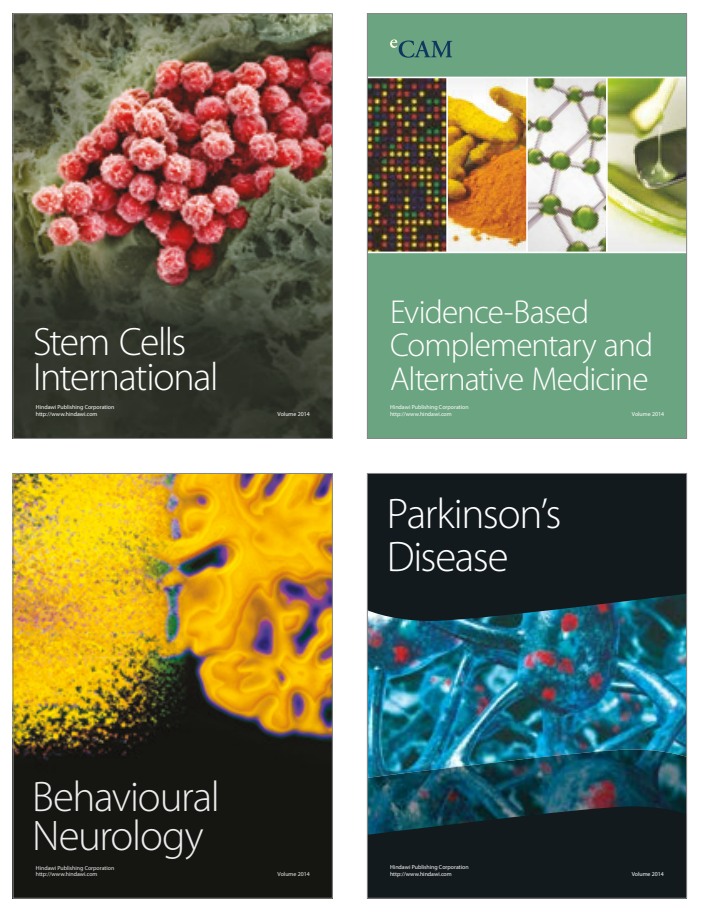
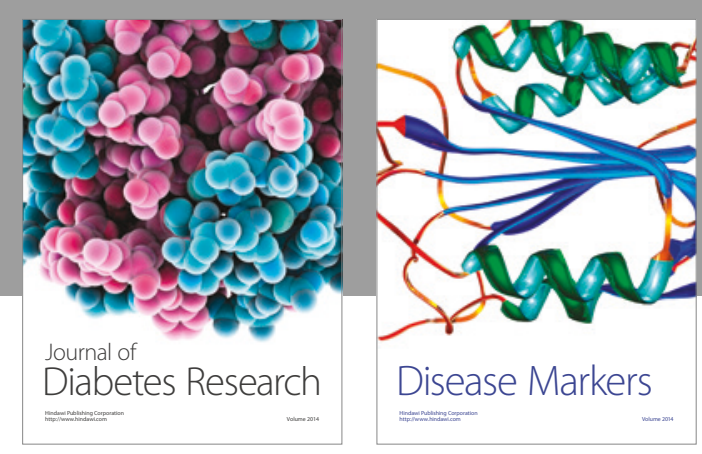

Disease Markers
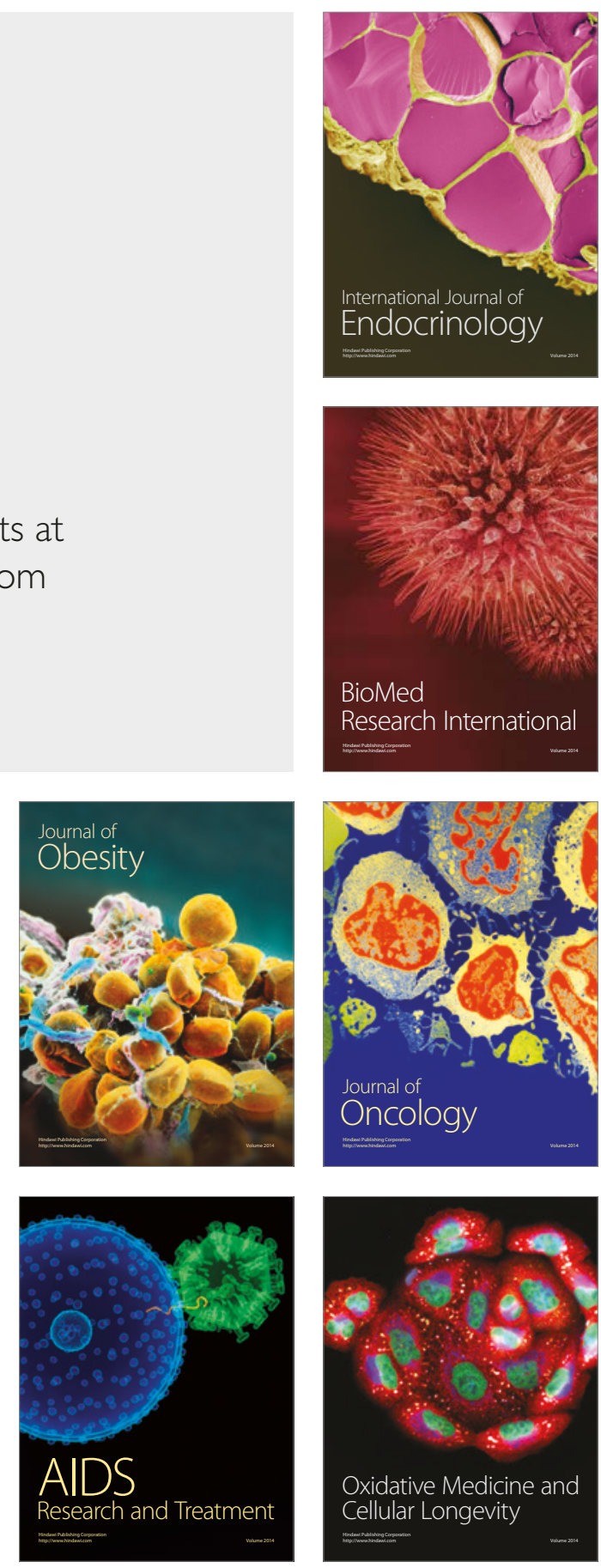